\title{
CARACTERIZAÇÃO DE ÁCIDOS GRAXOS, ÉSTERES METÍLICOS DE ÁCIDOS GRAXOS E ÓLEOS VEGETAIS EPOXIDADOS
}

\author{
F.C. LAGE, A.H. SUZUKI, A.S. FRANCA e L.S. OLIVEIRA \\ Universidade Federal de Minas Gerais, Departamento de Engenharia Mecânica \\ E-mail para contato: leandro@demec.ufmg.br
}

RESUMO - O objetivo deste trabalho foi de produzir e caracterizar ácidos graxos epoxidados (FA), ésteres metílicos de ácidos graxos epoxidados (FAME) e óleos vegetais epoxidados (VO) para serem usados como aglomerantes ou adesivos em materiais compósitos. Os FAs, FAMEs e VOs foram preparados utilizando ácido acético e peróxido de hidrogênio como reagentes e uma resina de troca iônica como catalisador. O Índice de Iodo foi determinado para os materiais precursores e seus respectivos produtos de epoxidação pelo método ASTM D5554. A espectroscopia no infravermelho médio por transformada de Fourier (FTIR) foi empregada para verificar a conversão de ligações duplas em anéis oxiranos e o teor de oxigênio oxirano foi determinado por titulação com ácido bromídrico. As viscosidades das resinas preparadas foram medidas com um viscosímetro Brookfield. As viscosidades das resinas preparadas, que permitem a definição da aplicação das mesmas, correlacionaram bem com os graus de insaturações dos materiais precursores e seus respectivos teores de oxigênio oxirano após a epoxidação.

\section{INTRODUÇÃO}

A utilização de óleos vegetais, bem como de ácidos graxos livres e de seus respectivos ésteres metílicos para a fabricação de resinas epóxi constitui uma alternativa sustentável em relação aos derivados da indústria petroquímica, por serem de fontes renováveis. Resinas epóxi produzidas de óleos vegetais podem ser utilizadas na fabricação de plastificantes com maior flexibilidade e estabilidade ao calor, de lubrificantes biodegradáveis e de materiais compósitos (Tayde et al., 2011). Os epóxidos são compostos altamente reativos, precursores de diversas substâncias como alcoóis e poliésteres (Tan e Chow, 2010). A reação de epoxidação de óleos vegetais, de ácidos graxos livres e de seus respectivos ésteres metílicos envolve duas etapas. Na primeira, produz-se o ácido peracético a partir de ácido acético e $\mathrm{H}_{2} \mathrm{O}_{2}$, mediante catálise ácida. Esta é a etapa limitante da reação, e torna-se impraticavelmente lenta sem a presença de catalisador ácido forte (Swern, 1970). Na segunda etapa, o ácido peracético reage com as insaturações presentes no óleo (ácidos graxos insaturados), ou seja, uma molécula de oxigênio é inserida em uma ligação dupla entre carbonos, formando um anel oxirano (epóxi). Dois métodos são comumente utilizados para a epoxidação de óleos vegetais, um por catálise homogênea com ácido sulfúrico e outro por catálise heterogênea com resinas de troca iônica fortemente ácidas, e.g., Amberlite IR-120 (Espinosa Pérez et. al. 2009).

Embora exista uma literatura abundante sobre a produção de resinas de óleos vegetais, de ácidos graxos livres e de ésteres metílicos de ácidos graxos epoxidados (Tan e Chow, 2010; Tayde et al., 2011), não há nenhum trabalho que explore as diferenças intrínsecas da obtenção destas resinas e de 


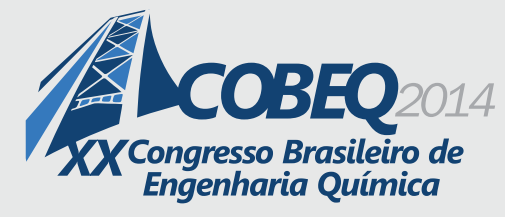

19 a 22 de outubro de 2014

Florianópolis/SC

suas respectivas propriedades quando se utilizam diferentes matérias-primas (e.g., óleos vegetais, ácidos graxos livres e ésteres metílicos de ácidos graxos). Portanto, constituiu objetivo deste trabalho a produção de resinas de óleos vegetais, de ácidos graxos livres e dos respectivos ésteres metílicos epoxidados e a determinação das respectivas propriedades.

\section{MATERIAIS E MÉTODOS}

Foram utilizados óleos comerciais de soja e de canola para a preparação de resinas e de ésteres metílicos de ácidos graxos. Os reagentes usados foram: metanol, ácido acético glacial, peróxido de hidrogênio $50 \%$, solução de iodo-cloro segundo Wijs, clorofórmio, amido, tiossulfato de sódio, iodato de potássio, iodeto de potássio, ácido clorídrico $35 \%$ e violeta de metila adquiridos da Synth (São Paulo, SP), metilato de sódio $30 \%$ em metanol e éter dietílico adquiridos da Vetec (São Paulo, SP), e Amberlite IR120 forma $\mathrm{H}^{+}$adquirida da Fluka Chemicals - Sigma Aldrich (São Paulo, SP).

A produção de ésteres metílicos de óleo de soja e de canola foi feita por rota convencional, em que são usados metanol como agente esterificante, e o catalisador $\mathrm{CH}_{3} \mathrm{ONa}$ em solução de metanol. Foi utilizada a proporção molar de 1:6 de óleo vegetal para metanol e 1,5\% em massa de catalisador. A reação foi conduzida a $60^{\circ} \mathrm{C}$ em reator de mistura encamisado, acoplado a banho ultra-termostato e a condensador de refluxo, sendo mantida por um período de $2 \mathrm{~h}$ para assegurar elevada conversão reacional. Após o término da reação, a mistura foi transferida para um funil de separação, do qual, após decantação e separação de fases, a glicerina foi removida. A purificação foi realizada com água destilada, e após separação de fases, a fase orgânica foi roto-evaporada para a remoção de água.

O método usado para epoxidação de óleos vegetais e de ésteres metílicos de ácidos graxos fundamentou-se no desenvolvido por Espinosa Pérez et. al. (2009). A matéria-prima foi adicionada ao reator encamisado, dotado de condensador de refluxo, juntamente com o catalisador Amberlite IR$120 \mathrm{H}$ e ácido acético glacial. A mistura foi aquecida até $70^{\circ} \mathrm{C}$, quando iniciou-se a adição gradual de $\mathrm{H}_{2} \mathrm{O}_{2}$. Após a adição do peróxido, a reação prosseguiu por $5 \mathrm{~h}$, sob agitação mecânica. Após $5 \mathrm{~h}$, a mistura final foi filtrada a vácuo para a separação do catalisador. $\mathrm{O}$ filtrado foi lavado diversas vezes com água destilada a $50^{\circ} \mathrm{C}$, até que a água residual atingisse $\mathrm{pH}$ neutro. Em seguida, a fase orgânica foi extraída e purificada com $200 \mathrm{~mL}$ de éter etílico. O solvente foi retirado da amostra em evaporador rotativo, a $45{ }^{\circ} \mathrm{C}$. Na etapa final, a amostra permaneceu em estufa overnight a $50{ }^{\circ} \mathrm{C}$ para remover o éter residual. Para o ácido oleico (livre), também foram realizadas reações com tempos de 3 e 4 horas para estudar o efeito na conversão relativa em oxigênio oxirano e na seletividade da reação.

A determinação do índice de iodo das matérias-primas e das resinas epóxi foi feita pela norma ASTM D5554-95 (2011). A quantidade de amostra de referência foi de $0,25 \mathrm{~g}$ para ácido oleico, óleos vegetais e ésteres alquílicos, e de 0,8 g para as resinas epóxi. Em Erlenmeyer de $500 \mathrm{~mL}$, foram pesadas as quantidades apropriadas de amostra e adicionado clorofórmio como solvente. $25 \mathrm{~mL}$ de solução de Wijs foram adicionados aos Erlenmeyers e as amostras foram mantidas no escuro por 30 min para permitir a ocorrência da reação. Após este tempo, adicionou-se aos frascos $20 \mathrm{~mL}$ de solução $15 \% \mathrm{p} / \mathrm{V}$ de iodeto de potássio. As soluções foram tituladas com solução de tiossulfato de sódio $0,1 \mathrm{~mol} / \mathrm{L}$ previamente padronizadas com iodato de potássio. A titulação foi feita até 


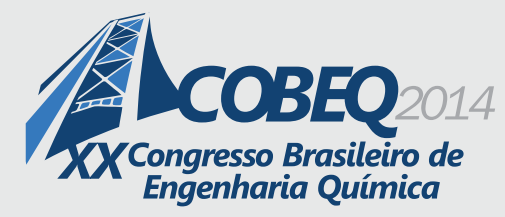

aparecimento de coloração alaranjada, quando adicionou-se a solução indicadora de amido. A titulação prosseguiu até que a solução mudasse de cor de azul para incolor. $O$ índice de iodo foi calculado pela equação:

$$
I V=\frac{12,69(B-S) N}{m}
$$

sendo IV o índice de iodo, $\mathrm{B}$ o volume de tiossulfato de sódio $\left(\mathrm{Na}_{2} \mathrm{~S}_{2} \mathrm{O}_{3}\right)$ gasto na titulação do branco, $\mathrm{S}$ o volume de $\mathrm{Na}_{2} \mathrm{~S}_{2} \mathrm{O}_{3}$ gasto na titulação da amostra, $\mathrm{N}$ a normalidade da solução de titulante e $\mathrm{m}$ a massa da amostra em gramas.

A determinação do teor de oxigênio oxirano seguiu metodologia descrita por Cooney (2009), envolvendo titulação com solução de ácido bromídrico $0,1 \mathrm{~mol} / \mathrm{L}$ em ácido acético. A solução titulada foi preparada com $0,4 \mathrm{~g}$ de resina epóxi adicionada de $10 \mathrm{~mL}$ de clorofórmio. A titulação ocorreu na presença de solução indicadora de violeta de metila em ácido acético $(1 \mathrm{~g} / \mathrm{L})$. A titulação prosseguiu até mudança de cor da solução de violeta para verde-azulado. A determinação do índice de iodo permite a estimativa do teor máximo de oxigênio oxirano de uma amostra, considerando-se $100 \%$ de conversão em ligações duplas e seletividade totalmente favorável ao oxigênio oxirano na reação:

$$
O O_{t}=\frac{I V_{0}}{2 A_{i}} \times A_{0} \times 100\left[100+\frac{I V_{0}}{2 A_{i}}\right]^{-1}
$$

sendo $\mathrm{OO}_{\mathrm{t}} \mathrm{o}$ teor máximo de oxigênio oxirano, $\mathrm{IV}_{\mathrm{o}} \mathrm{o}$ índice de iodo, $\mathrm{A}_{\mathrm{o}} \mathrm{o}$ número atômico do oxigênio e $A_{i} O$ número atômico do iodo. $O$ cálculo do percentual mássico de oxigênio oxirano é efetuado dos resultados das titulações com solução de $\mathrm{HBr} 0,1 \mathrm{~mol} / \mathrm{L}$ em ácido acético, conforme

$$
t=\frac{1,6 \times V \times N}{m}
$$

sendo t o teor percentual de oxigênio oxirano, $\mathrm{V}$ o volume em $\mathrm{mL}$ de solução de ácido bromídrico gasto na titulação, $\mathrm{N}$ a concentração desta solução em mol/L e m a massa da amostra em gramas. A conversão relativa em oxigênio oxirano é a razão entre o teor de oxigênio oxirano obtido e o máximo teor de oxigênio oxirano. A conversão de ligações duplas é calculada pela comparação dos índices de iodo da resina epóxi e da matéria-prima utilizada, conforme a equação

$$
D B C=100 \frac{\left(I V_{r m}-I V_{\text {resin }}\right)}{I V_{r m}}
$$

sendo DBC a conversão de ligações duplas, $\mathrm{IV}_{\mathrm{rm}} \mathrm{o}$ índice de iodo da matéria-prima e $\mathrm{IV}_{\text {resin }} \mathrm{o}$ índice de iodo da resina epóxi produzida. A seletividade do método é a razão entre a conversão de ligações duplas e a conversão relativa em oxigênio oxirano.

A Espectroscopia no Infravermelho Médio (FTIR) foi usada para verificar a formação de anéis oxirano nos óleos vegetais, ácidos graxos e respectivos ésteres metílicos. As análises foram realizadas em espectrômetro Shimadzu IR-Affinity (Japão) na faixa de $600-4000 \mathrm{~cm}^{-1}$, por ATR (Attenuated Total Reflectance) em um cristal de ZnSe. As determinações das viscosidades das resinas epóxi e das 


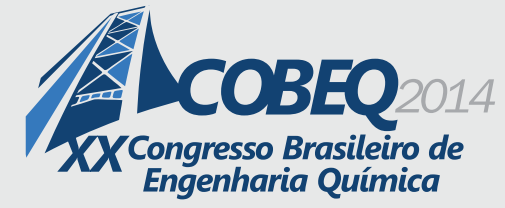

19 a 22 de outubro de 2014

Florianópolis/SC

respectivas matérias-primas foram feitas em viscosímetro digital Brookfield modelo DV-I PRIME, com spindle LV-2 em rotações apropriadas para a faixa de viscosidades das amostras, a $25^{\circ} \mathrm{C}$.

\section{RESULTADOS E DISCUSSÃO}

A caracterização das resinas foi efetuada por meio das análises de determinação do índice de iodo, determinação do teor mássico de oxigênio oxirano e FTIR. Os resultados para índice de iodo (em g de iodo por $100 \mathrm{~g}$ de amostra) para óleos vegetais, ácido oleico e ésteres metílicos são apresentados na Tabela 1. O índice de iodo é uma medida qualitativa do número de insaturações presentes na amostra, e um maior número de insaturações resulta em maior potencial de formação de grupos oxirano por epoxidação. $\mathrm{O}$ óleo de soja e os respectivos ésteres metílicos apresentaram os maiores percentuais máximos de oxigênio oxirano.

Tabela 1 - Resultados de índice de iodo para as matérias-primas utilizadas.

\begin{tabular}{|c|c|c|c|c|c|}
\hline Amostra & IV 1 & IV 2 & Média & Desvio Padrão & $\begin{array}{c}\text { \% Máximo de Oxigênio } \\
\text { Oxirano }\end{array}$ \\
\hline Óleo de Canola & 112,665 & 114,608 & 113,636 & 1,374 & 6,685 \\
\hline Óleo de Soja & 132,010 & 131,483 & 131,746 & 0,373 & 7,669 \\
\hline Ácido Oléico & 100,942 & 101,579 & 101,261 & 0,451 & 6,001 \\
\hline $\begin{array}{l}\text { Ésteres Metílicos de Óleo de } \\
\text { Canola }\end{array}$ & 98,364 & 99,203 & 98,784 & 0,593 & 5,862 \\
\hline $\begin{array}{l}\text { Ésteres Metílicos de Óleo de } \\
\text { Soja }\end{array}$ & 129,650 & 127,153 & 128,401 & 1,765 & 7,488 \\
\hline
\end{tabular}

Os resultados para os teores de oxigênio oxirano e conversões relativas são apresentados na Tabela 2.

Tabela 2 - Resultados de determinação de teor de oxigênio oxirano para resinas epóxi

\begin{tabular}{lcccccc}
\hline Matéria-prima & IV & $\begin{array}{c}\text { Máximo } \\
\text { Teor de } \\
\text { Oxigênio } \\
\text { Oxirano (\%) }\end{array}$ & $\begin{array}{c}\text { Teor de } \\
\text { Oxigênio } \\
\text { Oxirano } \\
\text { obtido (\%) }\end{array}$ & $\begin{array}{c}\text { Conversão } \\
\text { relativa em } \\
\text { oxirano (\%) }\end{array}$ & $\begin{array}{c}\text { Conversão de } \\
\text { ligações } \\
\text { duplas (\%) }\end{array}$ & $\begin{array}{c}\text { Seletividade } \\
\text { do método } \\
(\%)\end{array}$ \\
\hline Óleo de Canola & 1,100 & 6,685 & 6,266 & 93,729 & 99,032 & 94,644 \\
Óleo de Soja & 0,850 & 7,669 & 6,972 & 90,914 & 99,355 & 91,504 \\
Ácido Oleico (5h) & 2,014 & 6,001 & 2,364 & 39,394 & 98,011 & 40,194 \\
Ácido Oleico (4h) & 2,093 & 1,811 & 2,735 & 46,013 & 98,072 & 46,918 \\
Ácido Oleico (3h) & 4,040 & 2,293 & 3,107 & 51,784 & 96,873 & 53,455 \\
EMOC & 2,891 & 5,862 & 5,308 & 90,542 & 97,074 & 93,271 \\
EMOS & 2,454 & 7,488 & 5,322 & 71,073 & 98,089 & 72,458 \\
Remlam M & $=$ & $=$ & 6,890 & $=$ & $=$ & $=$ \\
\hline \multicolumn{7}{c}{ EMOC= Ésteres Metílicos de Óleo de Canola; EMOS= Ésteres Metílicos de Óleo de Soja. }
\end{tabular}




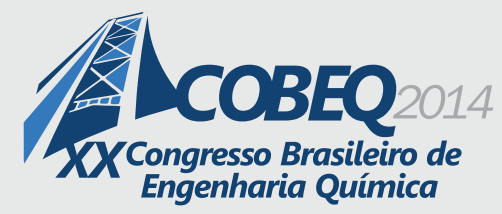

Os resultados demonstraram uma elevada conversão de ligações duplas ( $\sim 100 \%)$. A resina produzida de óleo de soja apresentou teor de oxigênio oxirano superior ao da resina comercial Renlam M, derivada do petróleo. Entretanto, a seletividade do método para algumas amostras não foi tão elevada, especialmente para as resinas preparadas com ácido oleico e com ésteres metílicos de óleo de soja. Isso pode ser atribuído à formação de alcoóis, por exemplo, após o processo de epoxidação por meio de reação de hidrólise catalisada por ácidos, devido à elevada instabilidade da estrutura epóxido. Pode se inferir que pelo ácido oléico apresentar uma cadeia carbônica menor que a dos óleos vegetais, este se torna mais susceptível à degradação pela ação catalisador Amberlite IR-120H (Campanella et al., 2011). Com a redução do tempo de reação, foram obtidos maiores teores mássicos de oxigênio oxirano e maiores conversões relativas em oxirano. Este resultado é indicativo da degradação do anel oxirano após a sua formação. Entretanto, ainda assim foram obtidas seletividades relativamente baixas $(\sim 50)$. As viscosidades das amostras de resinas epóxi preparadas são apresentadas na Tabela 3.

Tabela 3 - Resultados obtidos de viscosidades de resinas epóxi preparadas em laboratório

\begin{tabular}{lcccc}
\hline Amostra & Rotação(rpm) & $\mu(\mathrm{mPa} . \mathrm{s})$ & $\rho\left(\mathrm{kg} / \mathrm{m}^{3}\right)$ & $\gamma\left(\mathrm{mm}^{2} / \mathrm{s}\right)$ \\
\hline Ácido Oléico & 100,0 & $30,9-31,2$ & 895 & $34,5-34,9$ \\
Ácido Oléico Epoxidado (5h) & 5,0 & $6749-6764$ & 1100 & $6135-6149$ \\
Ácido Oléico Epoxidado (4h) & 50,0 & $482,3-482,9$ & 1100 & $438,5-439,0$ \\
Ácido Oléico Epoxidado(3h) & 50,0 & $349,7-350,3$ & 1100 & $317,9-318,5$ \\
Óleo de Canola & 100,0 & 62,4 & 920 & 67,8 \\
Óleo de Canola Epoxidado & 100,0 & $229,8-230,4$ & 810 & $283,7-284,4$ \\
Óleo de Soja & 100,0 & $54,9-55,2$ & 915 & $60,0-60,3$ \\
Óleo de Soja Epoxidado & 50,0 & $328,1-328,7$ & 870 & $377,1-377,8$ \\
EMOC & 100,0 & $12,9-13,2$ & 850 & $15,2-15,5$ \\
EMOC Epoxidados & 100,0 & 34,8 & 890 & 39,1 \\
EMOS & 100,0 & $10,8-11,1$ & 850 & $12,7-13,0$ \\
EMOS Epoxidados & 100,0 & $27,6-27,9$ & 890 & $31,0-31,3$ \\
Resina Comercial Renlam M & 10,0 & $2486-2489$ & 1100 & $2260-2263$ \\
\hline
\end{tabular}

$\mu$ : viscosidade dinâmica; $\rho$ : densidade; e $\gamma$ : viscosidade cinemática; EMOC= Ésteres Metílicos de Óleo de Canola; EMOS= Ésteres Metílicos de Óleo de Soja.

Comparando-se os resultados apresentados nas Tabelas 2 e 3, observa-se que, conforme esperado, a viscosidade dos óleos vegetais e também dos ésteres metílicos de ácidos graxos aumenta com o processo de epoxidação, pois a viscosidade é tanto maior quanto maior o grau de epoxidação. Entretanto, obtiveram-se aqui resultados diferentes para a epoxidação de ácido oleico, pois, a viscosidade foi tanto menor quanto maior o teor de oxigênio oxirano. Uma possível explicação para tal é a formação de dióis, que podem gerar estruturas rígidas e complexas devido à formação de fortes 


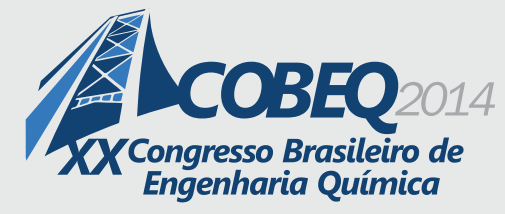

19 a 22 de outubro de 2014

Florianópolis/SC

interações moleculares por ligação de hidrogênio, tanto entre os grupos hidroxila quanto com grupos carbonila presentes na estrutura (Muturi et. al., 1994), contribuindo para o aumento da viscosidade. Para a resina epóxi produzida com tempo de reação de $5 \mathrm{~h}$, o valor de viscosidade é bastante expressivo, superior inclusive ao da resina epóxi comercial Renlam M. Para ésteres metílicos de ácidos graxos, observou-se uma redução de viscosidade em relação às dos óleos vegetais de origem, decorrente da redução da cadeia carbônica com o processo de transesterificação. Efetivamente, uma cadeia maior e mais ramificada de um composto orgânico está associada a maior viscosidade (Esteban et al., 2012). O mesmo efeito é observado para as resinas epóxi produzidas de ésteres metílicos, que apresentam menor viscosidade que dos respectivos óleos vegetais epoxidados.

O espectro em infravermelho obtido para resina epóxi comercial Renlam M é mostrado na Figura 1a. Observa-se que existe um pico bastante pronunciado associado ao oxigênio oxirano com número de onda $\sim 825 \mathrm{~cm}^{-1}$, característico de grupos epóxido. Este pico também existe nas resinas epóxi preparadas de óleos vegetais. Pode-se observar da Figura $1 \mathrm{~b}$ que os espectros do ácido oléico e do ácido oléico epoxidado são bastante semelhantes, com pequeno pico em $825 \mathrm{~cm}^{-1}$ (A). Este resultado está coerente com o de teor de oxigênio oxirano das resinas epóxi produzidas, com a resina de ácido oléico apresentando o pior resultado (Tabela 2). Além disso, podemos observar um pico em $\sim 3007 \mathrm{~cm}^{-1}$ (B) para o ácido oléico, mas com intensidade reduzida para o ácido oléico epoxidado. Este pico está associado a presença de insaturações nas moléculas do ácido graxo (Mungroo e Pradhan, 2008). Este fato está de acordo com o baixíssimo índice de iodo do ácido oleico epoxidado.

Os espectros no infravermelho para ésteres metílicos de óleo de canola e da respectiva resina epóxi são apresentados na Figura 2a e os para ésteres metílicos de óleo de soja e da respectiva resina epóxi na Figura 2b. Observa-se que a estrutura dos ésteres metílicos de ácidos graxos é bastante semelhante às dos ésteres metílicos epoxidados, tanto para o caso dos ésteres metílicos de óleo de canola quanto para os de óleo de soja. Entretanto, observam-se diferenças nos picos indicados nas Figuras por A e B, associados ao grupo epóxido das resinas e à presença de insaturações para os ésteres metílicos, respectivamente. Os espectros para óleos vegetais de soja e de canola e para os respectivos óleos epoxidados são apresentados nas Figuras $3 \mathrm{a}$ e $3 \mathrm{~b}$, apresentando o mesmo padrão discutido, com grande similaridade entre os espectros e os picos indicados em A e B, respectivamente associados ao grupo epóxido em $825 \mathrm{~cm}^{-1}$ e a presença de insaturações em $3007 \mathrm{~cm}^{-1}$.

\section{CONCLUSÃO}

Resinas epóxi foram produzidas tanto de óleos vegetais quanto de seus ésteres metílicos de ácidos graxos, utilizando metodologias convencionais da literatura. A variação de viscosidades das resinas produzidas permite direcioná-las para distintas aplicações em materiais compósitos, tanto aquelas que requerem uma resina mais rígida quanto aquelas que requerem uma resina mais flexível. $\mathrm{O}$ estudo realizado com as viscosidades das resinas epóxi e das matérias-primas demonstra que este parâmetro depende da complexidade e tamanho da cadeia carbônica e do teor de oxigênio oxirano da amostra. As resinas epóxi degradadas por catálise ácida apresentaram viscosidade extremamente elevada, fato decorrente das fortes interações intermoleculares por ligação de hidrogênio. 

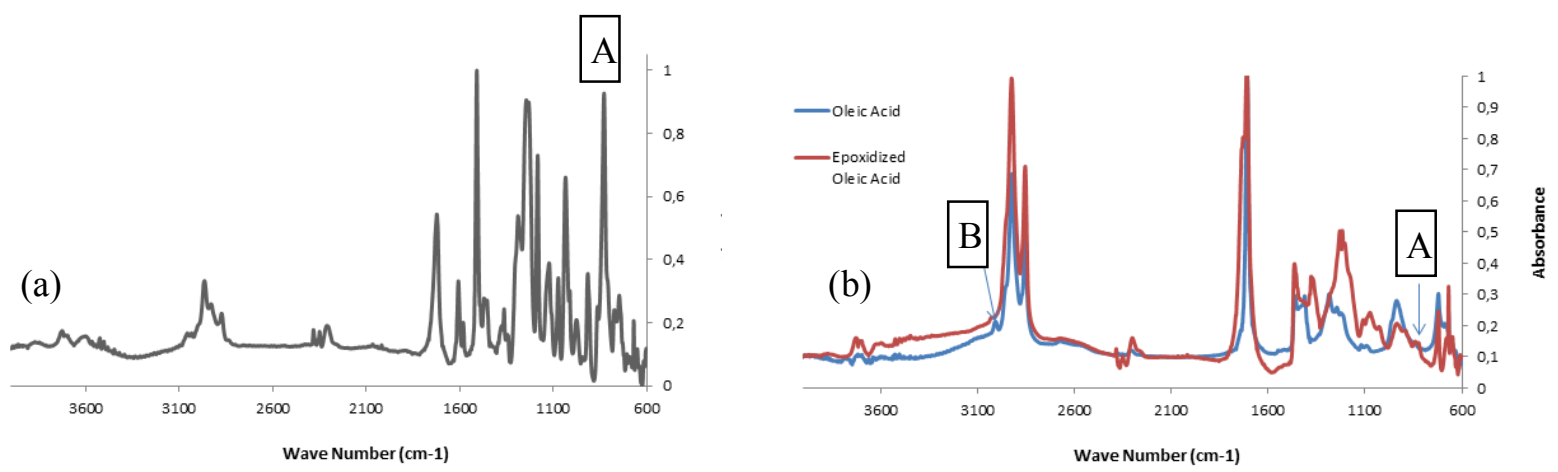

Figura 1 - Espectros no infravermelho médio para (a) resina comercial Renlam M e (b) ácido oleico e ácido oleico epoxidado.
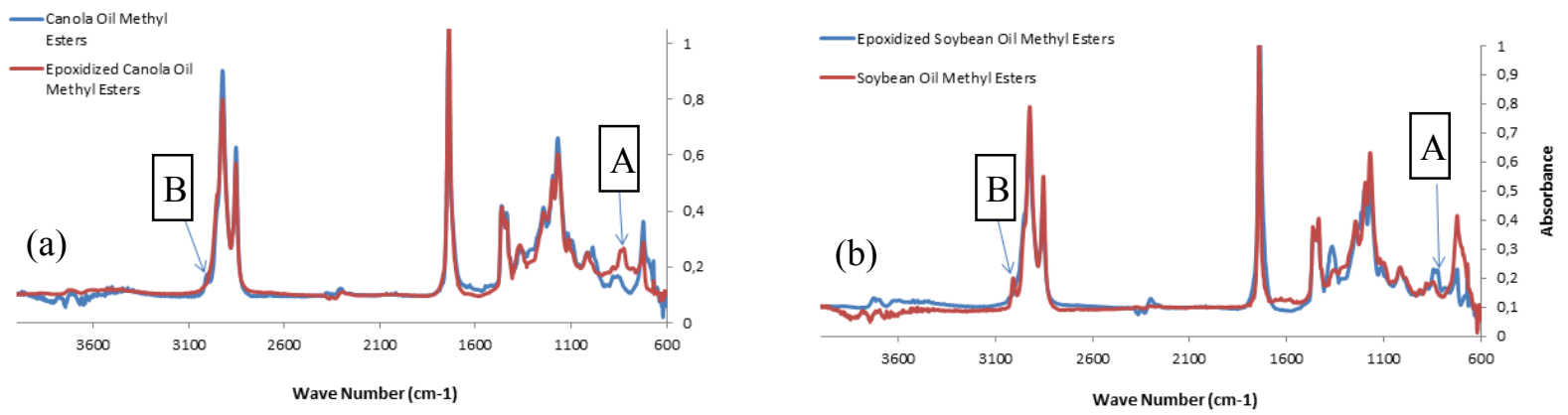

Figura 2 - Espectros no infravermelho médio para (a) ésteres metílicos de óleo de canola e da respectiva resina epóxi e (b) ésteres metílicos de óleo de soja e da respectiva resina epóxi.
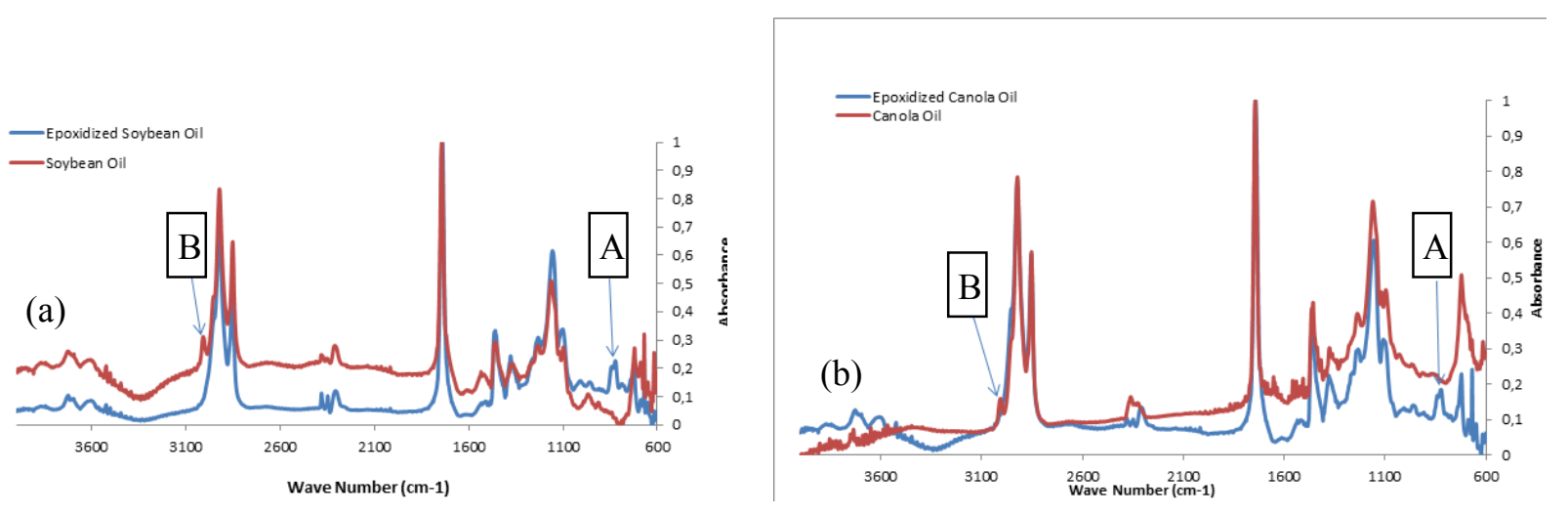

Figura 3 - Espectros no infravermelho médio para (a) óleo de soja e respectiva resina epóxi (b) óleo de canola e respectiva resina epóxi 


\section{REFERÊNCIAS BIBLIOGRÁFICAS}

ASTM International. "Standard Test for Determination of Iodine Value of Fats and Oils". ASTM D5554-95. West Conhohocken, PA, USA, 2011.

CAMPANElla, A.; BALTANÁS, M. A. Degradation of the oxirane ring of epoxidized vegetable oils in a liquid-liquid-solid heterogeneous reaction system. Chemical Engineering and Processing, vol. 46, p. 210-221, 2007.

COONEY, T. Epoxidized Resins from Natural Renewable Resources. Dissertação (Bachelor of Engineering - Mechanical). University of Southern Queensland, Faculty of Engineering and Surveying, 2009.

ESPINOSA PÉREZ, J. D.; HAAGENSON, D. M.; PRYOR, D. R.; ULVEN, C. A., WIESENBORN, D. P. Production and Characterization of Epoxidized Canola Oil. American Society of Agricultural and Biological Engineers, vol. 52, p.1289-1297, 2009.

ESTEBAN, B.; RIBA, J.R.; BAQUERO, G.; RIUS, A.; PUIG, R. Temperature Dependence of Density and Viscosity of Vegetable Oils. Biomass and Bioenergy, vol.42, p.164-171, 2012.

MUNGROO, R.; PRADHAN, N.C. Epoxidation of Canola Oil with Hydrogen Peroxide Catalyzed by Acidic Ion Exchange Resin. J Am Oil Chem Soc, vol. 85, p.887-896, 2008.

MUTURI, P.; WANG, D.; DIRLIKOV, S. Epoxidized Vegetable Oils as Reactive Diluents I. Comparision of vernonia, epoxidized soybean and epoxidized linseed oils. Progress in Organic Coatings, vol. 25, p. 85-94, 1994.

SWERN, D. Organic Peroxides. New York, USA. John Wiley and Sons, 1970.

TAN, S. G.; CHOW, W. S. Biobased Epoxidized Vegetable Oils and Its Greener Epoxy Blends: A Review. Polymer-Plastics Technology and Engineering, vol. 49, 1581-1590, 2010.

TAYDE, S.; PATNAIK, M.; BHAGT, S.L.; RENGE, V.C. Epoxidation of vegetable oils: A review. International Journal of Advanced Engineering Technology, vol. 2, p. 491-501, 2011.

\section{AGRADECIMENTOS}

Os autores agradecem o apoio financeiro das seguintes agências de fomento: CNPq e FAPEMIG. 